\title{
Estimate, a New iPad Application for Assessment of Plant Disease Severity Using Photographic Standard Area Diagrams
}

Sarah J. Pethybridge, ${ }^{\dagger}$ Cornell University, School of Integrative Plant Science, Plant Pathology \& Plant-Microbe Biology Section, Cornell University, Geneva, NY 14456; and Scot C. Nelson, College of Tropical Agriculture and Human Resources, Department of Tropical Plant and Soil Sciences, University of Hawaii at Manoa, Honolulu 96822

\begin{abstract}
Assessment of disease severity is a foundational component of plant pathology and essential for robust disease management. Researchers often estimate disease severity using standard area diagrams (SADs) that are reference images representing disease severity in percentage increments. SADs provide assessments of disease severity that are more accurate, precise, and reliable than other methods. Although specific SADs have been constructed for many plant diseases, they often depict severity in unrealistic black-and-white or grayscale illustrations. SADs are also usually printed, static references that can burden data collection in the field and require data to be transferred manually to a computer spreadsheet for manipulation. This data entry process and verification are prone to errors and require additional inputs of time and labor. We developed a new iPad application (app) called Estimate for researchers and crop managers for their use on a mobile device at the field-level for assessing plant disease severity in order to collect data or aid in treatment decisions. The app is a repository for digital, photographic SADs and offers savings in time for data collection and processing. Estimate allows users to select a disease

from a prepopulated list and specify the reference disease images in either logarithmic or linear intervals. Data may be collected as the midpoint of an interval (ordinal) or as $1 \%$ increments (continuous). Users then select among photographic images by touching those that best match the observed disease severity on successive samples. Estimate allows data entry at the plant and leaf hierarchical levels within plots and subplots. Alternatively, data may be collected on single sampling units with an undefined experimental design (i.e., 1 to $x$ leaves). The user may inspect and e-mail the final data in comma-separated values format for analysis using conventional spreadsheet software. Estimate was released with SADs for assessing the severity of Cercospora leaf spot in red and yellow table beet cultivars. A list of collaborators and up-to-date list of SADs included in Estimate is available at http://evade.pppmb.cals.cornell.edu/estimate/. SADs for other diseases will be added to Estimate as they become available. Estimate is available for free download from iTunes (https://itunes.apple.com/ WebObjects/MZStore.woa/wa/viewSoftware $\mathrm{id}=1193605571 \& \mathrm{mt}=8)$ and is compatible with an iPad Air 2 or equivalent using iOS 9.0 or greater.
\end{abstract}

The collection of accurate and precise data for disease severity is essential to many aspects of plant pathology and associated agricultural science disciplines. Severity can be defined as the percentage of a symptomatic area for a sampling unit (e.g., leaf, fruit, or plant) (Madden et al. 2007; Nutter et al. 1991, 2006). Operationally, disease severity can be quantified accurately and precisely by tools such as custom-built image analysis software available on stationary platforms such as Assess (Lamari 2002) or QUANT (Barbedo 2014) and mobile platforms such as Leaf Doctor (Pethybridge and Nelson 2015), or within freely available software such as ImageJ (Schneider et al. 2012). These tools usually require destructive sampling or photography and assessment of large numbers of sampling units in a relatively short period of time, which may be inconvenient and limit their utility due to restricted resources. As a trade-off, photos of sampling units do facilitate the preservation of a permanent record of disease severity and may be interrogated later to identify additional characteristics. Alternatively, visual estimation of disease severity is straightforward and may be conducted directly in the field or following destructive harvesting. However, an adverse consequence of such rapid assessment is the documented potential for error (Bock et al. 2008a,b, 2009, 2010a,b, 2015a,b, 2016; Chiang et al. 2014, 2016; Del Ponte et al. 2017; Nutter et al. 1993; Parker et al. 1995; Sherwood et al. 1983).

${ }^{\dagger}$ Corresponding author: S. J. Pethybridge; E-mail: sjp277@ cornell.edu

*The $\boldsymbol{e}$-Xtra logo stands for "electronic extra" and indicates that one supplementary figure is published online.

Accepted for publication 1 September 2017.

(c) 2018 The American Phytopathological Society
Standard area diagrams (SADs) were developed to improve the accuracy and precision of disease severity estimation by visually relating sampling units to reference images of known severities (Bock et al. 2016; Chiang et al. 2014, 2016; Del Ponte et al. 2017; James 1971, 1974). SADs are usually stylized, black-and-white images that represent the range of expected disease severities and are based on specific interval-scale assumptions (Bock et al. 2016; Del Ponte et al. 2017). For example, the Horsfall-Barratt scale defined categories with logarithmic intervals derived from the Weber-Fechner law. This law states that visual acuity is proportional to the log of intensity of a stimulus, inferring that the change in intensity of the stimulus (e.g., disease severity) is best represented by variation in logarithmic intervals (Horsfall and Barratt 1945). However, the value of logarithmic intervals based on the Weber-Fechner law has been discounted in favor of alternative (e.g., linear) intervals in several studies (Bock et al. 2008a, 2009, 2010a,b; Chiang et al. 2014; Christ 1991; Nutter and Esker 2006).

Most SADs are printed illustrations in unnatural color combinations, such as black and white or grayscale (Del Ponte et al. 2017; Schwanck and Del Ponte 2014). They are typically presented as static, printed reference materials. Data are recorded manually after comparing disease severity on an individual sampling unit to imagery in the SAD. However, this process subsequently requires manual transcription of data for analysis. Transcription is inherently fraught with human error and requires a substantial investment in time and resources for entry and checking (Easton et al. 2000; Rife and Poland 2015). Modern mobile devices can simplify and expedite the assessment of disease severity by using realistic photograph-based SADs and can minimize human error by reducing data transcription.

The objectives of this study were to develop an easy-to-use, semiautomatic, portable application (app) to contain photographic SADs. A secondary objective was to demonstrate the use of the app by 
development of SADs for Cercospora leaf spot (CLS) on table beet caused by the fungus Cercospora beticola Sacc. CLS is a significant constraint to table beet (Beta vulgaris subsp. vulgaris) production worldwide (Koike et al. 2010). Symptoms begin as small, gray, discrete lesions that coalesce and encompass entire leaves (McKay and Pool 1918; Weiland and Koch 2004). The lack of healthy leaves can cause the complete loss of table beet yield in broad-acre cropping systems due to the inability to harvest plants by top-pulling machinery (Kikkert et al. 2010; Stivers 2001). The table beet industry in New York currently supplies about 27,215 metric ton annually and is the second largest producer for the processing and fresh-beet markets in the United States (USDA-NASS 2012). CLS was the first disease selected for inclusion in the mobile app because of its consistent ranking as a high priority for research by the New York Vegetable Research Association and Council, and the need for crop scouts to rapidly and reliably assess disease severity on multiple sampling units. Rapid, in-field assessment of CLS severity is critical for the recommendation of disease management tactics to growers, including the timely application of fungicides.

\section{Development and Operation of the Estimate App}

Estimate was developed as an app for the iPad Air 2 or equivalent using iOS 9.0 or greater. Detailed instructions for Estimate are available on the "About" and "Instructions" screens navigated from the "Home" page (Fig. 1A). A future version will be developed for Android devices.

Creation of reference images for inclusion in SADs within the Estimate app. CLS-table beet SADs utilized diseased leaves collected during summer 2016 from broad-acre fields across western and central New York, pressed flat for photography. Separate SADs that reflect differences in symptoms and coalescence of lesions were derived from table beet cultivars Ruby Queen (red) and Touchstone Gold (yellow). For example, CLS lesions on Ruby Queen are numerous and small ( $\leq 0.5 \mathrm{~cm}$ in diameter) and tend to increase in number during the epidemic rather than coalesce. CLS lesions on Touchstone Gold are initially similar to those on Ruby Queen but rapidly coalesce and lack well-defined margins (Supplementary Fig. S1).

Leaves superimposed on a black velvet cloth background were photographed with the 8-megapixel iSight camera within the iPad Air 2, with an $f / 2.4$ aperture, at a height of $30 \mathrm{~cm}$ above the specimen. Editing of images corrected exposure anomalies and inconsistencies in hue and sharpened images (Adobe Photoshop Elements, version 12.1; Adobe Systems, San Jose, CA). The actual percent severity of each diseased leaf was quantified using the Leaf Doctor app (Pethybridge and Nelson 2015). Images with severities representing the approximate midpoint of the logarithmic and linear SADs (Table 1) were selected for use as photographic references. The SADs were designed to represent severities up to $100 \%$ because CLS causes complete leaf necrosis but not abscission (Koike et al. 2010).

Table 1. Interval range, midpoint, and actual severities represented by color photographic images of table beet leaves with Cercospora leaf spot caused by Cercospora beticola included in the logarithmic and linear standard area diagrams within the Estimate app ${ }^{\mathrm{a}}$

\begin{tabular}{lcc}
\hline Interval range (\%) & Midpoint $(\boldsymbol{\%})$ & Actual severity $(\boldsymbol{\%})^{\mathbf{b}}$ \\
\hline Logarithmic & $\ldots$ & None \\
0 & 1.5 & 2 \\
0 to 3 & 4.5 & 4.5 \\
3 to 6 & 9 & 10.4 \\
6 to 12 & 18.5 & 17.7 \\
12 to 25 & 37.5 & 39.6 \\
25 to 50 & 62.5 & 63.4 \\
50 to 75 & 81.5 & 86.2 \\
75 to 88 & 91 & 89.3 \\
88 to 94 & 96.5 & 92.3 \\
94 to 97 & 98.5 & 97.5 \\
97 to 100 & $\ldots$ & $\ldots$ \\
100 & & \\
Linear & $\ldots$ & $\ldots$ \\
0 & 5 & 5.5 \\
0 to 10 & 15 & 12.4 \\
10 to 20 & 25 & 27.1 \\
20 to 30 & 35 & 35.8 \\
30 to 40 & 45 & 48.6 \\
40 to 50 & 55 & 52.9 \\
50 to 60 & 65 & 62.7 \\
60 to 70 & 75 & 75.6 \\
70 to 80 & 85 & 83.3 \\
80 to 90 & 95 & 96.5 \\
90 to 100 & $\ldots$ & $\ldots$ \\
100 & & $\ldots$ \\
\hline
\end{tabular}

${ }^{a}$ Midpoint severity is recorded when the user selects to collect ordinal data.

b Actual CLS percent severity on a representative image quantified using Leaf Doctor (Pethybridge and Nelson 2015).
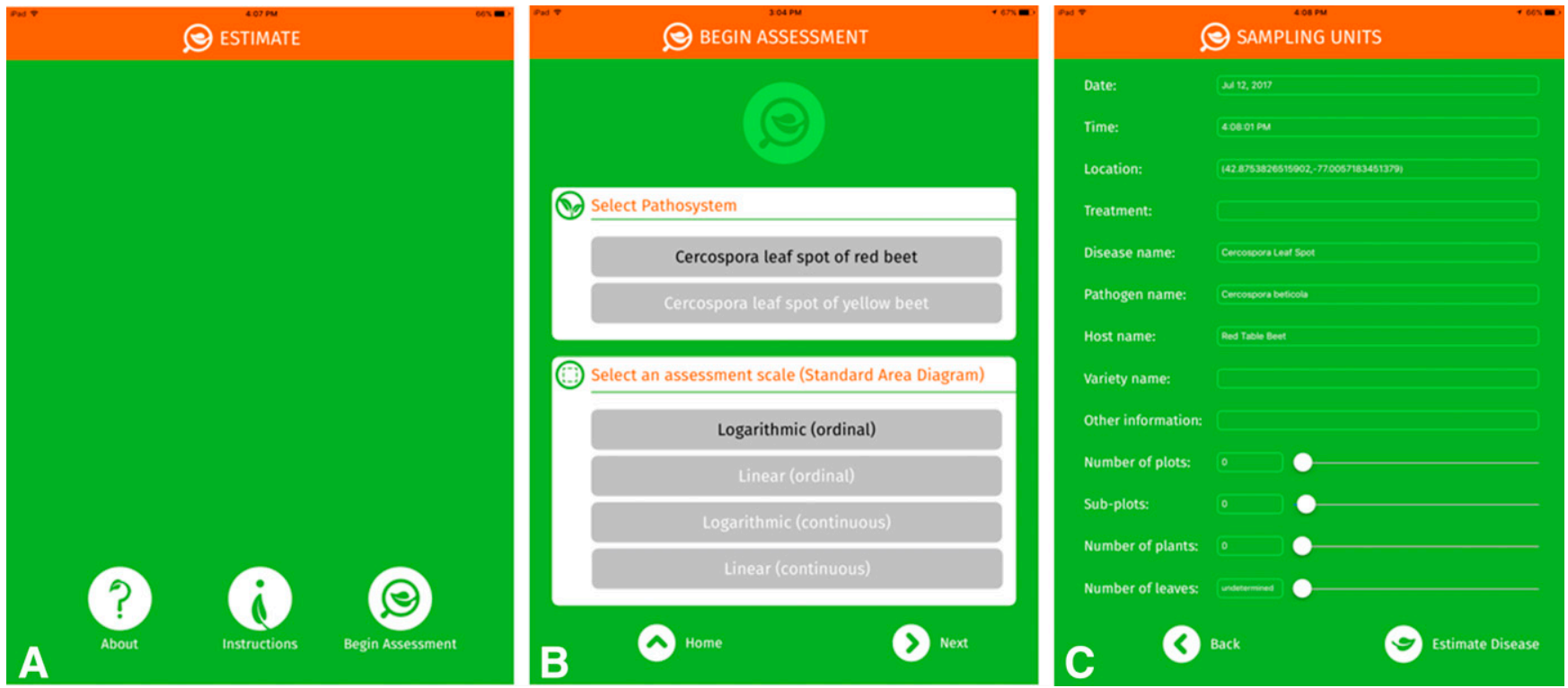

Fig. 1. Screenshots of the A, opening menu and home screen; B, "Begin Assessment" menu to select the pathosystem, assessment scale, and type of data to be collected; and C, "Sampling Units" screen provided for the user to specify the data collection structure including plots, subplots, plants, and leaves within the Estimate app. 


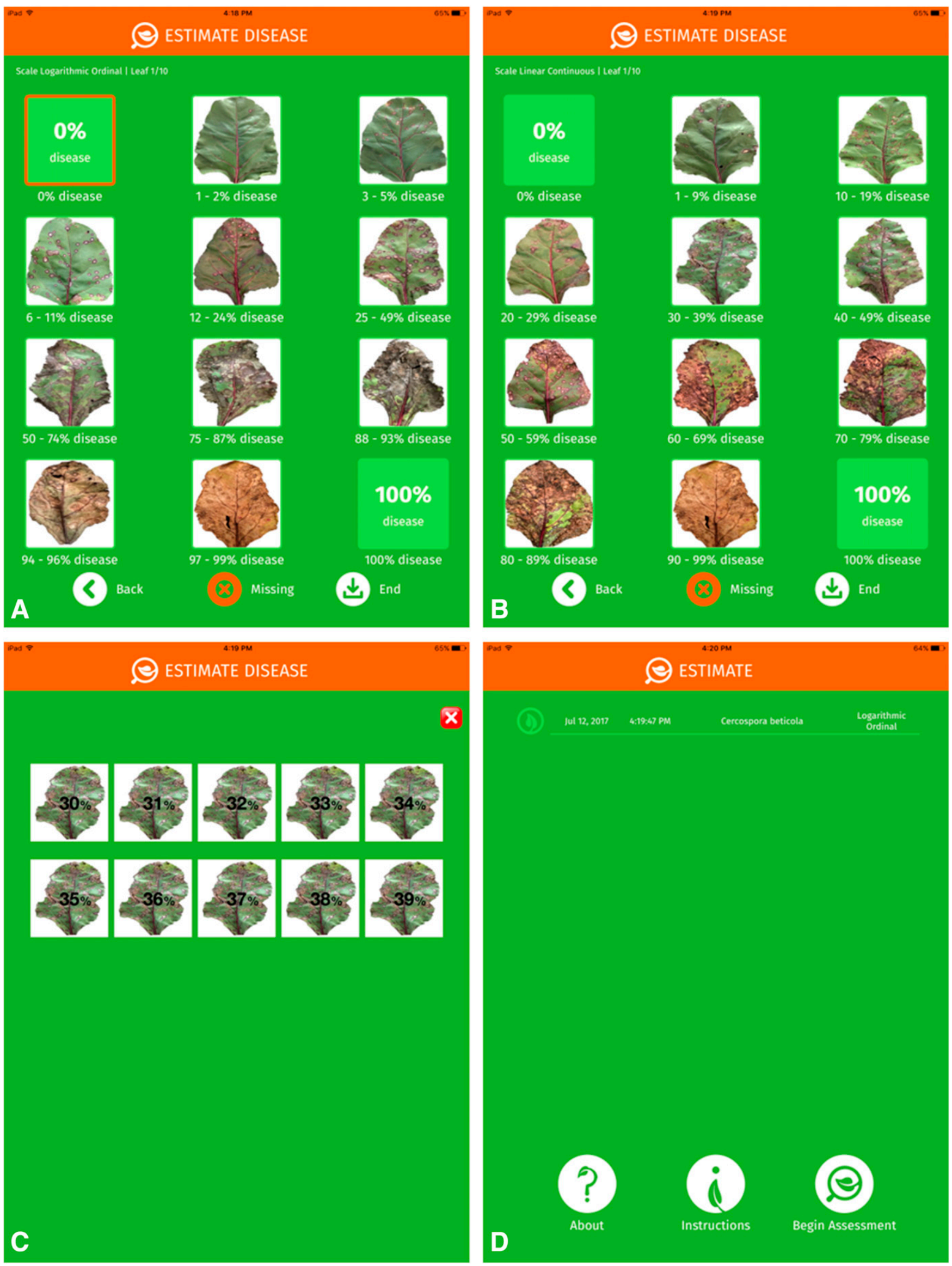

Fig. 2. Screenshots of standard area diagrams for Cercospora leaf spot of red table beet within the Estimate app representing A, logarithmic and B, linear interval scales. If ordinal data are selected within the "Begin Assessments" page using either the logarithmic or linear interval scales, the app collects the midpoint of the intervals. If continuous data are selected for either interval scale, selection of each image provides an additional screen for the user to select percent severity in $1 \%$ increments. C, Data are available for viewing, export by e-mail, or deletion from the "Home" page or $\mathbf{D}$, in color online. 
Operation of the Estimate app. Conducting estimates of disease severity using pictorial SADs is a sequential process guided by the user. A disease and assessment scale are first selected from the "Begin Assessment" page. The app provides users the ability to select between the logarithmic (Horsfall and Barratt 1945) or the linear assessment scale, and to collect either ordinal or continuous data (Fig. 1B). Metadata associated with the assessment project appear and may be entered on the "Sampling Units" page (Fig. 1C). Date, time, geospatial position, disease, pathogen, and host are automatically collated by the app and displayed on this page. The user can also provide optional text to specify details on the experimental treatments and host plant variety. On the "Sampling Units" page, the app also requests information from the user about how data will be collected (Fig. 1C). The user can select whether data will be recorded based on a hierarchical structure of plots (up to 200) or subplots (up to 30). Multiple sampling units on a plant or leaf level may be specified (up to 300) within each plot and subplot. Data may also be collected in the absence of a hierarchical plot structure for an undefined number of plant or leaf sampling units (Fig. 1C).

After the user specifies the assessment interval and data collection structure, the app displays an array of images representing the approximate, arithmetic midpoints of the intervals, logarithmic (Fig. 2A) or linear (Fig. 2B) (Table 1). The user selects the image that best represents each observed sampling unit in sequence. The data are recorded as either ordinal or continuous. If the user has specified ordinal data collection at the "Begin Assessment" page (Fig. 1B), the app records severity data as the midpoint of each interval selected. If continuous data are collected, the user may interactively select disease severity from 0 to $100 \%$ in $1 \%$ increments in subset ranges included within a parent category (Fig. 2C). The app displays the categorical images by cycling through the user-specified, sampling unit sequence. Missing sampling units appear as '.' in the output file. The user can interrupt data collection by saving the data and resuming the process at any point. After data collection completes, the app returns the user to the display page for datasets, ordered by time and date of collection (Fig. 2D). Users may view each dataset within the app, and delete or e-mail them in comma-separated value (csv) file format for further manipulation and analysis within standard software (Fig. 3). The user also may edit specific data points within the app.

\section{Discussion}

The Estimate app is a mobile repository for SADs with actual photographs of diseased sampling units. The highly flexible design allows incorporation of additional SADs for other diseases into the framework of the app. Options defined by the user within Estimate permit the collection of disease severity data from trials within a broad range of experimental designs, and export to other standard software for interrogation and analysis. The output file from Estimate preserves the structural information specified by the user, enabling rapid data manipulation (Fig. 3). One advantage of using Estimate for disease severity assessment is the time saved in data collection, transcription, and formatting. For example, the historical method for assessing CLS severity in table beet is counting the number of lesions on leaves (Abawi et al. 2014; Franc and Stump 2010; Pethybridge et al. 2016, 2017; Stump 2015) or visual assessment of severity on a per-plot basis using a linear scale to collect ordinal data (Abawi et al. 2005). In this study, estimation of severity using the Estimate app was approximately 10 times faster than counting lesions. In a replicated, small-plot trial conducted in 2016, lesions were counted on 700 leaves on each of five occasions to assess the efficacy of fungicides on temporal disease progress. On each assessment, lesion counting took approximately $3 \mathrm{~h}$. If a labor cost of $\$ 25 / \mathrm{h}$ is assumed, the total cost of lesion counting alone may be estimated at $\$ 1,125$. In addition to time spent counting lesions, the data must then be copied into a spreadsheet and verified manually to ensure that errors were not introduced during transcription (Easton et al. 2000). The reduced time required to assess CLS severity in table beet is expected to reduce rater fatigue and improve interrater reliability, which has been shown to be an important source of errors during disease severity estimation (Bock et al. 2015b; Chiang et al. 2014; Nutter and Esker 2006).

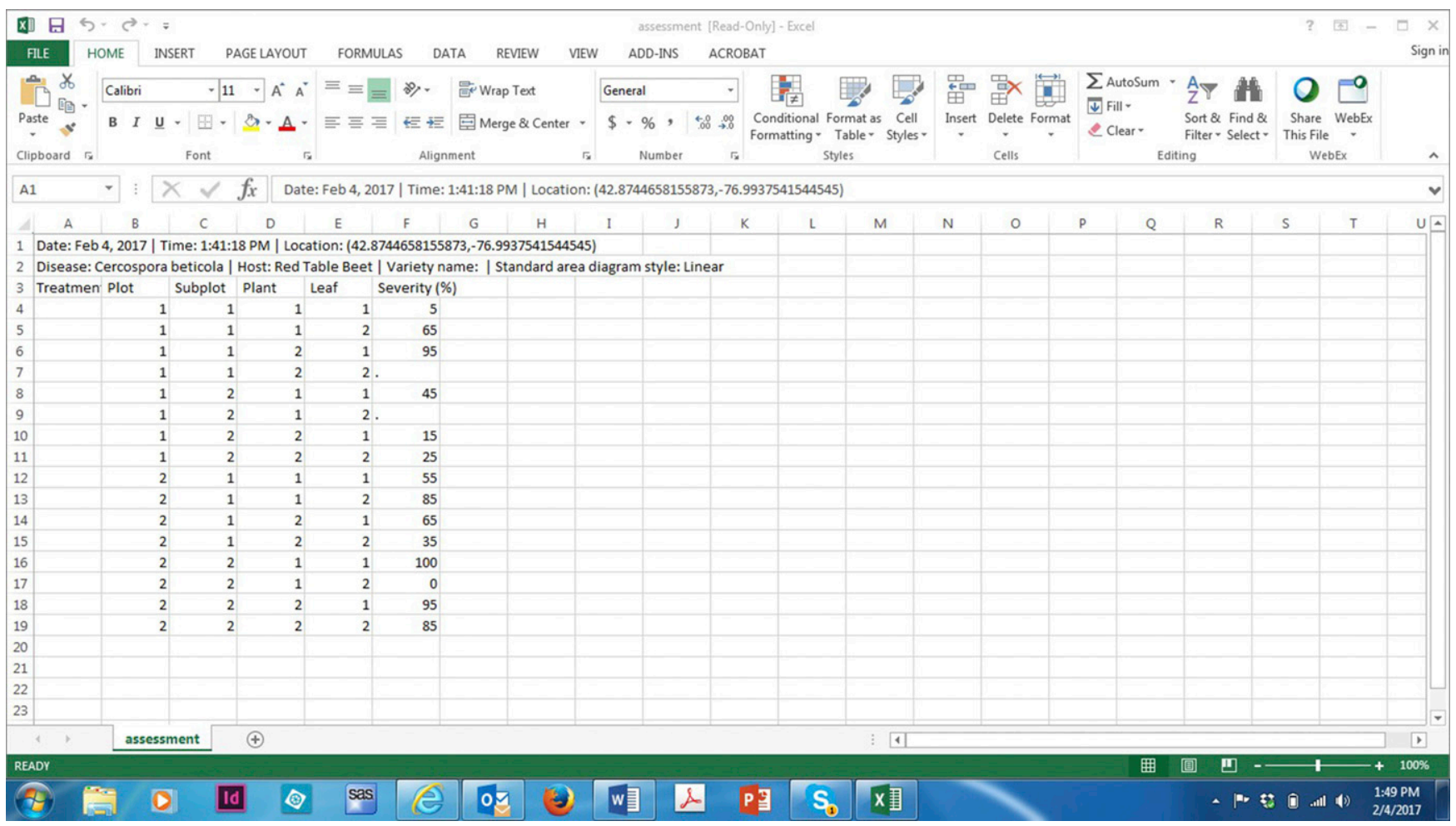

Fig. 3. Screenshot example of the output file provided by the Estimate app when data on disease severity at the plant and leaf sampling unit level is collected using a specified number of plots and subplots. Data are exported from the app as a comma-separated value file and can be opened in standard software for further examination. Periods in the severity (\%) column represent user-defined missing values. 
The provision of statistical evidence to demonstrate that adoption of SADs in disease severity estimation is beneficial to accuracy and precision is now considered standard (Bock et al. 2016; Del Ponte et al. 2017). We recommend consulting the best-practice guidelines for constructing SADs and reporting validation studies prior to selection of an interval scale and data type for a specific disease (Del Ponte et al. 2017). This includes selecting diseased specimens that represent the range of severities typically encountered in the field and noting the maximum severity. The actual severity for these reference images to be used in the SAD should be quantified using suitable image analysis software. Outcomes of studies to select the most accurate and precise interval scales have been mixed, depending upon disease symptoms such as lesion size and shape (Bock et al. 2008a, 2009, 2015b; Chiang et al. 2014). These findings highlight the need for disease-specific validation of SADs (Del Ponte et al. 2017) prior to use of this approach within Estimate.

The Estimate app allows users the flexibility to collect either ordinal or continuous disease severity data. Recording the midpoint of the selected interval scale produces ordinal data and requires appropriate analytical techniques to handle nonparametric data. The collection of continuous data enables the use of techniques suitable for analysis of parametric data. Analysis of nonparametric data for evaluating treatments can produce an elevated frequency of type II errors (Bock et al. 2016; Chiang et al. 2014; Del Ponte et al. 2017). We recommend that users consider the selection of suitable analysis techniques according to the nature of the data collected (Shah and Madden 2004).

A novel feature of the Estimate app is the use of digitized, color, and classified photographs of actual disease symptoms. The benefits of presenting reference images to raters in color over stylized blackand-white or grayscale images have been explored for some diseases such as rice brown spot (Schwanck and Del Ponte 2014). Color SADs have also been used for brown eyespot on coffee leaves (Custódio et al. 2011) and coffee cherries (Azevedo de Paula et al. 2016), and black rot of kale (Nuñez et al. 2017).

Estimate is a new, mobile platform that utilizes photographic SADs and offers flexible options to users for interval scale assumptions and collection of data on disease severity. The Estimate app is available for free download from iTunes to an iPad Air 2.0 or above with an iOS 9.0 or greater at (https://itunes.apple.com/WebObjects/ MZStore. woa/wa/viewSoftware?id=1193605571\&mt=8). User information is provided at the app website (http://evade.pppmb.cals. cornell.edu/estimate/) and includes a current list of SADs available within the app. Estimate was not developed for iPhones because their smaller screens do not have a sufficient display area for the SADs. Additional diseases selected for immediate inclusion in Estimate are Stemphylium leaf blight of onion (caused by Stemphylium vesicarium), leaf mold of tomato (caused by Passalora fulva), strawberry powdery mildew (caused by Sphaerotheca macularis), and Black Sigatoka of banana (caused by Mycosphaerella fijiensis). Users are encouraged to contact the authors to discuss developing new, digital SADs or integrating preexisting SADs for diseases or plant pests into future versions of Estimate.

\section{Acknowledgments}

Funding for the development of Estimate and standard area diagrams for CLS of table beet was provided by the United States Department of Agriculture-National Institute of Food and Agriculture (USDA-NIFA) Hatch project NYG-625424 managed by The New York State Agricultural Experiment Station, Cornell University, Geneva and USDA-NIFA Hatch project HAW08036-H (accession number 1010616) managed by the College of Tropical Agriculture and Human Resources, University of Hawaii at Manoa. We thank D. Ionel (Adelante Consulting Inc., Canada) for app coding, C. Tomcsak (Thinkrs Creative Studio, Canada) for design and graphics, and F. Brooks (University of Hawaii at Manoa) for his constructive comments on an earlier draft of this manuscript.

\section{Literature Cited}

Abawi, G. S., Kikkert, J. R., Moktan, K., Lange, H. W., and Smart, C. D. 2014. First report of resistance to Quadris among populations of Cercospora beticola causing leaf spot of table beet in New York State. (Abstr.) Phytopathology 104:S1.1.

Abawi, G. S., Ludwig, J. W., and Gugino, B. K. 2005. Evaluation of fungicides for the control of pocket rot and leaf spot of table beet, 2004. Plant Dis. Manage. Rep. 60:V146.
Azevedo de Paula, P. V. A., Pozza, E. A., Santos, L. A., Chaves, E., Maciel, M. P. and Paula, J. C. A. 2016. Diagrammatic scales for assessing brown eye spot (Cercospora coffeicola) in red and yellow coffee cherries. J. Phytopathol. 164:791-800.

Barbedo, J. G. A. 2014. An automatic method to detect and measure leaf disease symptoms using digital image processing. Plant Dis. 98:1709-1716.

Bock, C. H., Chiang, K.-S., and Del Ponte, E. M. 2016. Accuracy of plant specimen disease severity estimates: Concepts, history, methods, ramifications and challenges for the future. CAB Rev. 11:1-21.

Bock, C. H., Gottwald, T. R., Parker, P. E., Cook, A. Z., Ferrandino, F., Parnell, S., and van den Bosch, F. 2009. The Horsfall-Barratt scale and severity estimates of citrus canker. Eur. J. Plant Pathol. 125:23-38.

Bock, C. H., Gottwald, T. R., Parker, P. E., Ferrandino, F., Welham, S., van den Bosch, F., and Parnell, S. 2010a. Some consequences of using the HorsfallBarratt scale for hypothesis testing. Phytopathology 100:1030-1041.

Bock, C. H., Hotchkiss, M. W., and Wood, B. W. 2015a. Assessing disease severity: Accuracy and reliability of rater estimates in relation to number of diagrams in a standard area diagram set. Plant Pathol. 65:261-272.

Bock, C. H., Jarroudi, M. E., Kouadio, L. A., Mackels, C., Chiang, K. S., and Delfosse, P. 2015b. Disease severity estimates-Effects of rater accuracy and assessment methods for comparing treatments. Plant Dis. 99:1104-1112.

Bock, C. H., Parker, P. E., Cook, A. Z., and Gottwald, T. R. 2008a. Characteristics of the perception of different severity measures of citrus canker and the relationships between the various symptom types. Plant Dis. 92:927-939.

Bock, C. H., Parker, P. E., Cook, A. Z., and Gottwald, T. R. 2008b. Visual rating and the use of image analysis for assessing different symptoms of citrus canker on grapefruit leaves. Plant Dis. 92:530-541.

Bock, C. H., Poole, G. H., Parker, P. E., and Gottwald, T. R. 2010b. Plant disease severity estimated visually, by digital photography and image analysis, and by hyperspectral imaging. Crit. Rev. Plant Sci. 29:59-107.

Chiang, K. S., Bock, C. H., El Jarroudi, M., Delfosse, P., Lee, I. H., and Liu, H. I 2016. Effects of rater bias and assessment method on disease severity estimation with regard to hypothesis testing. Plant Pathol. 65:523-535.

Chiang, K. S., Liu, S. C., Bock, C. H., and Gottwald, T. R. 2014. What interva characteristics make a good categorical disease assessment scale? Phytopathology 104:575-585.

Christ, B. J. 1991. Effect of disease assessment method on ranking potato cultivars for resistance to early blight. Plant Dis. 75:353-356.

Custódio, A. A. P., Pozza, E. A., Guimarães, S. S. C., Koshikumo, E. S. M., Hoyos, J. M. A., and Souza, P. E. 2011. Comparison and validation of diagrammatic scales for brown eye spots in coffee tree leaves. Cienc. Agrotec. 35:1067-1076.

Del Ponte, E. M., Pethybridge, S. J., Bock, C. H., Michereff, S. J., Machado, F. J., and Spolti, P. 2017. Standard area diagrams for aiding severity estimation: Scientometrics, pathosystems and methodological trends in the last 25 years. Phytopathology 107:1161-1174.

Easton, K. L., McComish, J. F., and Greenberg, R. 2000. Avoiding common pitfalls in qualitative data collection and transcription. Qual. Health Res. 10: 703-707.

Franc, G., and Stump, W. L. 2010. Cercospora leaf spot management with foliar fungicide programs, 2009. Plant Dis. Manage. Rep. 4:FC006.

Horsfall, J. G., and Barratt, R. W. 1945. An improved grading system for measuring plant disease. (Abstr.) Phytopathology 35:655.

James, W. C. 1971. An illustrated series of assessment keys for plant diseases, their preparation and usage. Can. Plant Dis. Surv. 51:39-65.

James, W. C. 1974. Assessment of plant diseases and losses. Annu. Rev. Phytopathol. $12: 27-48$.

Kikkert, J. R., Reiners, S., and Gugino, B. K. 2010. Row width, population density, and harvest date effects on marketable yield of table beet. HortTechnology 20: 560-567.

Koike, S. T., du Toit, L. J., and Abawi, G. S. 2010. Cercospora leaf spot of vegetable crops in the Chenopodiaceae. Pages 91-96 in: Cercospora Leaf Spot of Sugar Beet and Related Species. R. T. Lartey, J. J. Weiland, L. Panella, P. W. Crous, and C. E. Windels, eds. American Phytopathological Society, St. Paul, MN.

Lamari, L. 2002. ASSESS: Image Analysis Software for Plant Disease Quantification. American Phytopathological Society, St. Paul, MN.

Madden, L. V., Hughes, G., and van den Bosch, F. 2007. The Study of Plant Disease Epidemics. American Phytopathological Society, St. Paul, MN

McKay, M. B., and Pool, V. W. 1918. Field studies of Cercospora beticola Phytopathology 8:119-136.

Nuñez, A. M. P., Monteiro, F. P., Pacheco, L. P., Rodriguez, G. A. A., Nogueira, C. C. A., Pinto, F. A. M. F., de Medeiros, F. H. V., and de Souza, J. T. 2017. Development and validation of a diagrammatic scale to assess the severity of black rot of crucifers in kale. J. Phytopathol. 165:195-203.

Nutter, F. W., Jr., and Esker, P. D. 2006. The role of psychophysics in phytopathology: The Weber-Fechner law revisited. Eur. J. Plant Pathol. 114: 199-213.

Nutter, F. W., Jr., Esker, P. D., and Netto, R. 2006. Disease assessment concepts and the advancements made in improving the accuracy and precision of plant disease data. Eur. J. Plant Pathol. 115:95-103.

Nutter, F. W., Jr., Gleason, M. L., Jenco, J. H., and Christians, N. C. 1993 Assessing the accuracy, intra-rater repeatability, and inter-rater reliability of disease assessment systems. Phytopathology 83:806-812. 
Nutter, F. W., Jr., Teng, P. S., and Shokes, F. M. 1991. Disease assessment terms and concepts. Plant Dis. 75:1187-1188.

Parker, S. R., Shaw, M. W., and Royle, D. J. 1995. Reliable measurement of disease severity. Asp. Appl. Biol. 43:205-214.

Pethybridge, S. J., and Nelson, S. C. 2015. Leaf Doctor: A new portable application for quantifying plant disease severity. Plant Dis. 99:1310-1316.

Pethybridge, S. J., Vaghefi, N., and Kikkert, J. R. 2016. Efficacy of fungicides for the control of Cercospora leaf spot in processing table beet, 2015. Plant Dis. Manage. Rep. 10:V003.

Pethybridge, S. J., Vaghefi, N., and Kikkert, J. R. 2017. Management of Cercospora leaf spot in conventional and organic table beet production. Plant Dis. 101:1642-1651.

Rife, T. W., and Poland, J. A. 2015. Field Book: An open-source application for field data collection on Android. Crop Sci. 54:1624-1627.

Schneider, C. A., Rasband, W. S., and Eliceiri, K. W. 2012. NIH to ImageJ: 25 years of image analysis. Nat. Methods 9:671-675.

Schwanck, A. A., and Del Ponte, E. M. 2014. Accuracy and reliability of severity estimates using linear or logarithmic disease diagram sets in true colour or black and white: A study case for rice brown spot. J. Phytopathol. 162: 670-682.

Shah, D. A., and Madden, L. V. 2004. Nonparametric analysis of ordinal data in designed factorial experiments. Phytopathology 94:33-43.

Sherwood, R. T., Berg, C. C., Hoover, M. R., and Zeiders, K. E. 1983. Illusions in visual assessment of Stagonospora leaf spot of orchard grass. Phytopathology 73:173-177.

Stivers, L. 2001. Crop Profile: Beets in New York. Online publication. Cornell Cooperative Extension Bulletin. http://pmep.cce.cornell.edu/fqpa/crop-profiles/ beet.html

Stump, W. 2015. Management of Cercospora leaf spot with foliar fungicide programs, 2014. Plant Dis. Manage. Rep. 9:FC125.

USDA-NASS. 2012. Quick Stats. Online Publication. United States Department of Agriculture-National Agricultural Statistics Service. https://quickstats.nass. usda.gov/

Weiland, J., and Koch, G. 2004. Sugar beet leaf spot disease (Cercospora beticola Sacc.). Mol. Plant Pathol. 5:157-166. 